\title{
Abortion counselling according to healthcare providers: A qualitative study in the Lisbon metropolitan area, Portugal
}

\author{
Vanda Beja and Isabel Leal \\ Psychology and Health Research Unit, Instituto Superior de Psicologia Aplicada, Lisbon, Portugal
}

A B S T R A C T Objective To gain a deeper understanding of healthcare providers' perceptions on the abortion counselling they provide and its usefulness.

Method We conducted in-depth interviews with 16 healthcare providers working in the Lisbon metropolitan area. The interviews were then subjected to content analysis.

Results We identified the following themes on abortion counselling description: receiving the woman and understanding her request; providing information; supporting decisionmaking; managing emotional and psychological issues; addressing contraception; managing third-party involvement; offering psychological counselling; informing about the State's support and offering social counselling. All participants described counselling as useful but valued different aspects of it: information provision; addressing contraception to prevent future unplanned pregnancy/abortion; emotional support; decision-making support; addressing emotional issues beyond abortion; enticing women to seek healthcare in the future; preventing poor emotional post-abortion adjustment. Counselling was considered of no use to change the woman's abortion decision.

Conclusion The abortion counselling provided in Portugal is in tune with the latest literature on the subject, following a client-centred approach focused on the provision of information and emotional support. It can be improved, however, particularly in what concerns the staff's communication and counselling skills. Further research is needed to improve the provision of abortion care in Portugal.

K E Y W O R D S Abortion; Counselling; Healthcare providers; Portugal; Content analysis

\section{N T R O D U C T I O N}

Before 2007, induced abortion in Portugal was allowed only on the grounds of fetal anomalies (up to 24 weeks), risk for the woman's health (up to 12 weeks) or suspicion of rape (up to 16 weeks).
Although these indications still apply, since 2007 abortion on request may be legally performed up to ten completed weeks of gestation, regardless of the woman's reasons for having it done $\mathrm{e}^{1,2}$. 
According to the current legal regulations ${ }^{3-7}$, a woman seeking an abortion must attend a compulsory preliminary consultation aimed at establishing gestational age; collecting clinical data; providing her with the necessary information to decide whether the pregnancy will continue or be terminated; advising her on the abortion method and post-abortion contraception. A compulsory three days reflexion period follows, during which she may obtain voluntary psychological and/or social counselling (provided by a psychologist and a social worker, respectively). She can then freely discuss her choice and/or receive additional information about the support the State may provide to continue the pregnancy. Before the procedure, she (or, if under 16 years old, her legal guardian) must give written informed consent. The abortion may be carried out by pharmacological or surgical means; a follow-up consultation takes place two weeks later. The woman should select and initiate a method of contraception immediately after the abortion. In addition, a contraception follow-up consultation must be scheduled within two weeks post-abortion. Women are entitled to be accompanied by a person of their choice through the entire abortion process. All information provided at any stage should be accompanied by official written information drawn up by the Direcção-Geral da Saúde (DGS, the Portuguese Health State Department).

Induced abortion in Portugal requires the provision of accurate information on the following issues: gestational age; medical and surgical abortion (clinical procedures, side effects, indications, contraindications, advantages, disadvantages, risks, possible complications, instructions to be followed pre- and postabortion); legal and administrative requirements (time frames, places and staff to resort to, existence of a compulsory reflexion period, documents required); possibility of obtaining psychological and social counselling; State support to continue the pregnancy; contraception follow-up consultation ${ }^{3-7}$. In sum, health professionals are required to provide 'general abortion counselling'.

Prior to 2007, most abortions took place illegally or outside the country ${ }^{1,8}$. Although relevant research was conducted on illegal abortion ${ }^{8}$ and abortion in case of rape or for fetal or maternal indications ${ }^{9}$, available data were scarce, incomplete and unreliable. In the last three years, research on legal abortion has been done $\mathrm{e}^{10}$ and several scientific meetings were held. However, there is still much to learn about the new Portuguese reality. Since 2007, induced abortions carried out in the country must be registered on-line and sent to the DGS monthly by abortion providers ${ }^{4,7}$. This database, which continuously monitors abortion across the country, will be useful for future research. However, it does not and cannot cover all relevant information, including abortion counselling. Data on this aspect are currently lacking in Portugal ${ }^{10,11}$.

Literature on abortion counselling worldwide comprises guidelines ${ }^{12-17}$ and contributions of health professionals and institutions working in the field ${ }^{18,19}$, based mainly on clinical practice and unsupported by theoretical frameworks. Yet, some authors have presented abortion counselling models that follow specific theoretical approaches (e.g., feminist ${ }^{20}$, cognitive $^{21}$ ) and both qualitative $\mathrm{e}^{22,23}$ and quantitative ${ }^{24,26}$ studies have been conducted. Still, more research is needed.

Much of the available literature suggests a clientcentred approach (focused on the specific needs of each client) and emphasises the importance of clientprovider interaction in the provision of care $^{14,15,20,21,27,28}$. Based on the contributions of several authors ${ }^{12-17,20,21,27,28}$, we identified what we call key-elements with regard to abortion counselling, namely, principles that should guide the intervention of healthcare providers to guarantee good quality client-provider interactions, thus, good quality care. These key-elements are (1) confidentiality and privacy, (2) neutrality, a nonjudgmental attitude and respect for the client's decisions, (3) empathy and client-centred effective communication, and (4) technical knowledge and basic counselling skills. According to the same sources, abortion counselling comprises the following dimensions: (1) decisionmaking support; (2) provision of information and obtainment of informed consent; (3) emotional support and screening of psychosocial risk situations; (4) management of third-party involvement; (5) counselling on contraception and other sexual and reproductive health $(\mathrm{SRH})$ issues ${ }^{11}$.

Abortion counselling is consistently described as useful. Its benefits include (1) more positive and respectful client-provider interactions resulting in higher client satisfaction; (2) less negative feelings and pain related to lack of clinical information; (3) greater compliance to follow-up care and effective contraception (although some research ${ }^{29}$ shows 
otherwise); (4) prevention and management of poor emotional post-abortion adjustment; (5) clients' increased participation in the protection and promotion of their own health by further seeking healthcare in the future ${ }^{12,14,16,26-28}$.

Healthcare providers both witness and actively participate in the abortion process. Hence, it makes sense to ask them about the obstacles and flaws they come across in their daily work in order to come up with solutions. Moreover, their perceptions on abortion in general and the women they work with in particular have important effects on the way they act towards them ${ }^{14,16,30-32}$. Comparing their perceptions with those of women may help us understand if healthcare providers fully comprehend the circumstances and experiences of the persons they assist. Research on abortion counselling can contribute to increase the feeling of satisfaction of the staff and promote an effective use of the available resources. It may both lead to new research questions and contribute to enhance the quality of the care provided.

The aim of this study was to gain a deeper understanding of the perceptions of healthcare personnel on the guidance they provide throughout the abortion process: what the counselling consists of, how useful they find it and why.

\section{METHODS}

\section{Design}

We used a qualitative, descriptive and exploratory design and carried out in-depth interviews to collect detailed information that was subjected to content analysis. This technique is appropriate to describe phenomena without using pre-established hypotheses, and to organise and classify qualitative data ${ }^{33}$.

\section{Participants}

Participants were 16 abortion counselling providers working in the Lisbon metropolitan area who were selected by means of a convenience, heterogeneity and snowball sampling method. Due to the exploratory and descriptive nature of the study, we tried to address a variety of counselling experiences, thus, selected participants with various professions, working in several types of healthcare institutions, and providing diverse types of counselling, in different settings. As we initiated the data collection, we asked the interviewees to refer other people in the field who might have different experiences from theirs and be willing to participate. The characteristics of the sample are described in Table 1.

Table 1 Characteristics of the participants $(N=16)$

\begin{tabular}{|c|c|}
\hline Characteristics & $N=1$ \\
\hline \multicolumn{2}{|l|}{ Sex } \\
\hline Female & 14 \\
\hline Male & 2 \\
\hline \multicolumn{2}{|l|}{ Age (Range: 24-55) } \\
\hline$<25$ & 1 \\
\hline $25-34$ & 7 \\
\hline $35-44$ & 1 \\
\hline$\geq 45$ & 7 \\
\hline \multicolumn{2}{|l|}{ Profession } \\
\hline Psychologist & 7 \\
\hline Nurse & 5 \\
\hline Doctor* & 3 \\
\hline Social worker & 1 \\
\hline \multicolumn{2}{|l|}{ Type of healthcare institution } \\
\hline NHS primary care health centre & 7 \\
\hline NHS general or maternity hospital & 5 \\
\hline Private clinic & 2 \\
\hline Non-governmental organisation & 2 \\
\hline \multicolumn{2}{|l|}{ Type of counselling ${ }^{* *}$} \\
\hline General & 9 \\
\hline Psychological & 3 \\
\hline General and psychological & 3 \\
\hline General and social & 1 \\
\hline \multicolumn{2}{|l|}{ Counselling setting } \\
\hline In person & 15 \\
\hline Via telephone & 1 \\
\hline \multicolumn{2}{|c|}{$\begin{array}{l}\text { Stage of the abortion process in which the } \\
\text { participant provided counselling }\end{array}$} \\
\hline All stages of the abortion process & 10 \\
\hline Before and after the abortion $\dagger$ & 6 \\
\hline
\end{tabular}

*Two general practitioners and one gynaecologist/obstetrician.

* * Some participants provided more than one type of counselling. All psychological counselling was provided by psychologists and social counselling by social workers. One psychologist provided only general counselling. $\dagger$ All respondents who provided counselling before and after the abortion worked in NHS primary care health centres, where the preliminary consultation and the contraception follow-up consultation take place but the abortion itself may not be carried out. 


\section{Procedure}

Data were collected between October 2007 and May 2008. Participants were informed of the research goals and the means of the data collection. They were also told that all information gathered would be used solely for investigation purposes and that both participants and institutions would remain anonymous. Only one institution, Clínica Os Arcos - Lisboa, explicitly asked to be identified.

We conducted 16 semi-structured individual indepth interviews using a script comprising two questions: (1) "What does the abortion counselling you provide consist of?" and (2) "How useful do you consider that counselling to be and why?" This script was conceived both to help the interviewer conduct the encounters and encourage participants to freely discuss the topics addressed. In most encounters, the interviewer felt the need to clarify what had been said, invite the participant to further develop a particular topic and/or explore issues that were not part of the script but emerged during the interview. The encounters took place face to face, lasted 30 to 90 minutes each, and were fully audiorecorded.

\section{Data analysis}

Interviews were transcribed verbatim and subjected to content analysis in accordance with Bardin's ${ }^{34}$ and Vala's ${ }^{33}$ recommendations. An initial coding frame was derived both from the literature and from a preliminary reading of the material. During the coding process, the initial categories and subcategories were adjusted, and new ones were created. The final coding frame was obtained using a mixed method of categories and subcategories' definition - a priori and a posteriori. We used sentences as the recording unit (RU - the specific segment of content that is characterised by placing it in a given category) and paragraphs as the context unit (the larger segment of content used by coders to assign RUs to categories) ${ }^{35}$. However, when sentences expressed more than one idea we divided them into several RUs to fit into different categories or subcategories.

To guarantee reliability, two different analysts coded parts of the data and compared their analyses, discussing and solving inconsistencies (reproducibility criterion). One of the analysts coded all the material on three different occasions, always obtaining the same analysis (stability criterion). All collected data were coded (exhaustivity criterion) and each RU was inserted in one single category or subcategory (exclusivity criterion).

In addition to the thematic analysis, we conducted a frequency analysis, using frequency of occurrence as the enumeration unit (the unit based on which the coders quantify the material) ${ }^{35}$. We considered both the number of RUs found for each category and subcategory in the whole corpus (i.e., the total number of RUs in a category or subcategory) and the number of interviews with RUs that fall into a given category or subcategory (i.e., the number of participants that mentioned a category or subcategory). Given the descriptive and exploratory nature of our study, we emphasised the thematic analysis in detriment of the frequency analysis, which was used mainly to attain an idea of the relative weight of different themes.

\section{R E S U L T S}

\section{Description of abortion counselling}

We identified the following themes among the respondents' descriptions of the abortion counselling:

(1) Receiving the woman and understanding the abortion request, understanding the context in which the pregnancy occurred, and identifying its desirability and meaning to the woman and her reasons to end it.

(2) Providing information, and clarifying any doubts related to the abortion process, including clinical, legal and practical information. This was done by all participants but one, who did not mention it. Clinical information (on procedures, risks, possible complications, instructions to be followed pre- and post-abortion) was the most frequently provided type of information (46\% of all RUs in the category 'Information Provision' and mentioned by 14 interviewees).

(3) Supporting abortion decision-making. This comprises the creation of an environment where the woman feels she is heard and free to discuss, reflect on and clarify her abortion decision (ten respondents mentioned it). It also includes ascertaining that the woman has pondered her 
choice, feels as little ambivalent as possible, reached the decision herself and considers it to be the most sensible one in those particular circumstances of her life (six respondents mentioned this). All interviewees thought that most women had made up their mind by the time they approached the abortion service.

(4) Managing emotional and psychological issues. This pertains to the provision of emotional support (77\% of all RUs in the category and mentioned by seven respondents), monitoring the woman's emotional state (four interviewees mentioned this), discussing future plans regarding pregnancy and motherhood, and screening for previous psychopathology (each of these subcategories was mentioned by one participant). It was the dimension of counselling mentioned by the smallest number of interviewees (eight respondents).

(5) Addressing contraception issues. It involves evaluating contraceptive measures applied before the abortion (ten respondents), promoting awareness and behavioural change in this regard (eight respondents), providing information (nine respondents), negotiating, selecting and prescribing/delivering a contraceptive (nine respondents), promoting the uptake of a contraceptive method that fits the woman's characteristics (six participants), monitoring her intention to comply to contraception starting soon after the abortion (five respondents), and referring her to the contraception follow-up consultation or other related services (13 respondents).

(6) Managing third-party involvement. It includes ensuring whether the woman wants a third-party to be present, screening for- and managing situations of pressure/coercion and/or disagreement within the couple about pregnancy outcome, and counselling the third-party separately or in the woman's presence. All participants accepted the presence of a third-party, except for two who worked in an institution that only allowed it in special circumstances. Five usually received the woman alone before calling in a third-party, whereas five others saw them together through the entire process. The remaining respondents did not mention how they proceeded.

(7) Offering psychological counselling. This was mentioned by 14 interviewees. The approach differed depending on the institution. In four, the staff member who conducted the preliminary consultation was the one who mentioned the possibility of psychological counselling but only to some women, according to their characteristics and circumstances. In two institutions, that staff member informed all women about this service. In one institution, all pregnant teenagers attended an initial Psychology consultation, whether they sought abortion or not, while adult women requesting abortion were all presented with this option by the staff member who received them. In another institution, all women seeking abortion attended an initial consultation with the psychologist.

(8) Informing about the State's support and offering social counselling. Most participants (14) mentioned this dimension of counselling. However, only two (who worked in the same institution) discussed the State's support with all and informed them about the possibility to resort to social counselling. The other respondents only proceeded this way with women they thought were in a situation that justified it, namely: abortion requests for mainly financial reasons; women financially deprived who wished to continue the pregnancy; acute ambivalence towards pregnancy; abortion requests after ten gestational weeks; women who needed financial aid to acquire contraceptives that were not provided free of charge; domestic violence.

Table 2 summarises the frequency analysis of the categories related to abortion counselling description.

\section{Usefulness of abortion counselling}

All participants described the abortion counselling they provided as useful, relevant or important but valued different aspects of it (Table 3).

Eight respondents thought counselling was useful in terms of information provision, which allows the staff to obtain the woman's informed consent and eases her anxiety towards the abortion process. Half of the study group considered it useful to address contraception issues, and, hence, prevent future unplanned pregnancy/abortion. Eight participants thought that emotional support was the element that made counselling useful, while six felt that it was decision-making 
Table 2 Description of abortion counselling according to the 16 interviewees - Frequency analysis

\begin{tabular}{|c|c|c|c|}
\hline Category & $\begin{array}{l}\text { Total number } \\
\text { of } R U s \text { in the } \\
\text { category }\end{array}$ & $\begin{array}{l}\% \text { of } R U \text { in } \\
\text { the category }\end{array}$ & $\begin{array}{c}\text { Number of } \\
\text { respondents who } \\
\text { mentioned the category }\end{array}$ \\
\hline $\begin{array}{l}\text { Receiving the woman and understanding } \\
\text { the abortion request }\end{array}$ & 14 & $4 \%$ & 9 \\
\hline Providing information & 52 & $15 \%$ & 15 \\
\hline Supporting abortion decision-making & 40 & $11 \%$ & 10 \\
\hline Managing emotional and psychological issues & 35 & $10 \%$ & 8 \\
\hline Addressing contraception issues & 104 & $29 \%$ & 16 \\
\hline Managing third-party involvement & 50 & $14 \%$ & 12 \\
\hline Offering psychological counselling & 27 & $8 \%$ & 14 \\
\hline $\begin{array}{l}\text { Informing about the State's support and } \\
\text { offering social counselling }\end{array}$ & 32 & $9 \%$ & 14 \\
\hline Total & 354 & $100 \%$ & - \\
\hline
\end{tabular}

Table 3 Usefulness of abortion counselling according to the 16 interviewees - Frequency analysis

\begin{tabular}{lccc}
\hline Category & $\begin{array}{c}\text { Total number } \\
\text { of RUs in the } \\
\text { category }\end{array}$ & $\begin{array}{c}\text { \% of } R U \text { in } \\
\text { the category }\end{array}$ & $\begin{array}{c}\text { Number of } \\
\text { respondents who } \\
\text { mentioned the category }\end{array}$ \\
\hline Information provision & 13 & $20 \%$ & 8 \\
Addressing contraception issues to $\quad 11$ & $17 \%$ & 8 \\
$\quad$ prevent unplanned pregnancy/abortion & 17 & $25 \%$ & 7 \\
Emotional support & 14 & $22 \%$ & 6 \\
Decision-making support & 5 & $8 \%$ & 4 \\
Eddressing emotional issues beyond abortion & 2 & $3 \%$ & 2 \\
Prevention of poor emotional post-abortion adjustment & 3 & $5 \%$ & 1 \\
Total & 65 & $100 \%$ & - \\
\hline
\end{tabular}

support. However, these participants only considered decision-making support relevant in the following circumstances: when the woman shows no ambivalence but finds in counselling a support for her decision; and in the rare cases where she is truly ambivalent and counselling can guarantee that she reaches the decision that best suits her. Furthermore, half of the respondents thought counselling was of no use to promote a decision change since most women approached abortion services with their choice made and did not change their mind with counselling. The fact that counselling might be an opportunity for women to address emotional issues beyond the abortion itself was what made it useful for four respondents, mostly psychologists. Two participants pointed out that a good counselling experience might entice women to seek healthcare services in the future and one psychologist stressed the fact that it could help prevent poor emotional post-abortion adjustment.

Finally, three respondents mentioned the importance of receiving specific training on abortion care and sharing their experiences in peer discussion groups to improve their intervention.

\section{I S C U S S I O N}

Our results on both abortion counselling description and its usefulness are consistent with the literature on the subject ${ }^{12-17,20,21,27,28}$.

The counselling provided by the interviewees follows a client-centred approach that focuses on the provision of information and emotional support 
according to the needs of each client. This suggests that Portuguese healthcare providers are acting according to current guidelines and models ${ }^{12-}$ $17,20,21,27,28$ instead of following an outdated approach focused on the prevention of post-abortion emotional sequelae and the provision of decision-making support that used to be more common until the early $1980 s^{18,19,21}$. Research has shown that most women do not exhibit post-abortion emotional sequelae, except in specific situations related either to individual characteristics or particular life circumstances ${ }^{36}$. It is also known that, when they approach an abortion service, many women have already pondered on their situation and made a decision ${ }^{12,21,37}$. Our interviewees were very aware of this.

The results on the management of emotional and psychological issues show that, although a majority of participants regarded it as important, only half described it as part of the counselling they provided. This suggests that certain respondents did not feel comfortable with or capable of providing this particular dimension of care. All literature on this subject emphasises the fact that a good client-provider interaction requires both empathy and effective clientcentred communication $^{12-15,20,21,27,28}$. It is, therefore, essential to provide health professionals with the necessary tools to meet these requirements, including: (1) mastering basic communication and counselling skills; (2) feeling comfortable and drawing pleasure from their role as counsellors; and (3) being aware of prejudice or personal beliefs that might affect the way they act towards women. Achieving this requires initial and continued training, as well as monitoring the counselling provided through clinical supervision, discussion groups, and anonymous client evaluation $^{16,30-32}$. Three interviewees explicitly mentioned the need for training and clinical discussion groups.

Offering psychological counselling was described by most participants as part of their intervention, which is not surprising since it is required by law. Nevertheless, we found some variability regarding the way this service was presented. We believe this reflects the fact that institutions differ in their modus operandi and, although we do not consider it to be a problem, it may have implications that are discussed elsewhere ${ }^{11}$. Portuguese law requires women seeking abortion to be informed of the possibility of attending psychological counselling, yet this was not the procedure in a number of institutions.
Offering social counselling and referring to the State's support were also mentioned by most respondents. Again, this is not surprising since that procedure is required by law. However, only one institution applied it to all women. In all others, these issues where addressed solely in specific cases. Several participants pointed out that, for most women, it made no sense to discuss social issues because they were not seeking abortion mainly for financial reasons and/or the State's support was not enough to make them reconsider their choice. From our point of view, this seems a reasonable approach. Addressing social or financial issues might also make a woman who seeks abortion for totally unrelated reasons feel inadequate or guilty. In this regard, the current Portuguese law seems to mirror mainstream social representations on femininity, motherhood and abortion ${ }^{19,23}$. Furthermore, as pointed out by Murphy ${ }^{19}$, it draws a dividing line between a 'selfish' choice and a 'responsible' one, emphasising the unacceptability of abortion for women financially capable of supporting a child and ignoring the fact that they might not want to become mothers ever or they feel unprepared to raise a child at that particular time of their lives. These arguments and the results of our study suggest the need to conduct research on women's thoughts and feelings towards this dimension of counselling in order to determine whether it should remain compulsory.

Twelve respondents mentioned involving a thirdparty in counselling. As recommended by law and several authors ${ }^{12-17,21}$, third-party involvement was only allowed if the woman desired it. Some participants saw her alone before calling in a thirdparty, whereas others met with both from the very beginning. We find the first procedure more appropriate as it preserves the woman's privacy and enhances the chances to identify coercion/pressure. One institution only allowed third-party involvement in special circumstances. This procedure is contrary to what is required by law and prevents women from feeling supported by persons whose presence means a lot to them, when they desire it. Research suggests that the support of such persons or the lack of it have an important impact on women's abortion experience $^{38}$.

As described earlier, the participants' intervention when a third-party was involved included screening for and managing cases of pressure/coercion or disagreement within the couple about pregnancy 
outcome and, less frequently, providing counselling to persons escorting the woman. These findings suggest that those persons seldom show enough distress to justify the provision of individual or specialised counselling. On the other hand, healthcare providers may not be taking full advantage of third-party involvement in abortion counselling. If women consent to it, contraceptive issues could be addressed with partners since it may enhance their involvement in this regard and contribute to prevent future unplanned pregnancy ${ }^{39}$. When relationship problems emerge during the abortion process, counselling can address these issues or the couple can be referred for specialised counselling ${ }^{40}$. It is vital, however, to ensure that women desire third-party involvement in counselling; research on how women feel about this is needed. Counsellors should have the necessary skills to identify in which cases third-party involvement is appropriate, to conduct it effectively and to know when to refer clients for specialised counselling.

All participants claimed to discuss contraception during counselling and half considered it useful because, in doing so, they could help prevent future unplanned pregnancy/abortion. This line of thought is in tune with most data in the literature that emphasise the impact of abortion counselling on contraceptive uptake and its preventive function in this re$\operatorname{gard}^{13,14,17,24-28}$

Like two of our interviewees pointed out, a good counselling experience might entice women to call on healthcare services in the future, particularly SRH care services. The attitudes and communication/counselling skills of health professionals are of paramount importance in this regard ${ }^{30,31}$. They must be aware of their own prejudices and beliefs to avoid a judgmental or patronising behaviour towards women that might dissuade them from seeking further care or adversely affect their compliance to contraceptives.

Several authors claim that abortion counselling may be a good opportunity to address SRH issues other than contraception, including the screening and prevention of sexually transmitted infections $^{13,14,24,27}$. The fact that this did not come up in the interviews leads us to believe that it is no part of the counselling provided by the interviewees. Yet discussing these and other relevant SRH matters might benefit women.
This study partially depicts what happened on the ground during the first six to 12 months after the law changed, in 2007. It has obvious limitations. It resorted to a small non-probability sample that included only healthcare providers working in the Lisbon metropolitan area. It would be interesting to replicate the investigation in other regions of the country, especially rural areas, where things may be different. Given the fact that the study is based on an account of what abortion counselling is and not on its direct observation, the results may not reflect the reality.

Since abortion on request has only been legal for a short time in Portugal, certain aspects of its implementation have yet to be investigated, with a view to improving abortion care. Important areas of research are: clients' satisfaction with the services; adequacy and effectiveness of different models of abortion care; the impact of counselling on the way women and those who accompany them experience the abortion process and on contraceptive behaviour and post-abortion SRH; conscientious objection and its impact on the access to abortion. Finally, it would be interesting to compare the results of this study with the accounts of women and those who accompany them and to replicate this study five to ten years from now with the same participants in order to determine what changes may have taken place.

This study reveals that the abortion counselling conducted in Portugal is in tune with the current literature, and that it follows a client-centred approach which focuses on information and emotional support provision. It also shows that abortion counselling is perceived by healthcare providers as a useful service in various ways. Nonetheless, it can be improved, especially, with regard to the staff's communication and counselling skills. Further research is needed to improve the provision of abortion care in Portugal.

\section{A C K N O W L E D G E M E N T S}

We acknowledge with gratitude Constança Carvalho for her help in the final editing of this paper and Amarília Cabaços for reviewing its English translation.

Declaration of interest: The authors report no conflicts of interests. The authors alone are responsible for the content and writing of the paper. 


\section{R E F E R E N C E S}

1. Vilar D. Abortion: The Portuguese case. Reprod Health Matters 2002;10:156-61.

2. Oliveira da Silva M. Reflections on the legalisation of abortion in Portugal. Eur J Contracept Reprod Health Care 2009;14:245-8

3. Lei n. ${ }^{\circ}$ 16/2007, de 17 de Abril - Exclusão de ilicitude nos casos de interrupção voluntária da gravidez, Diário da República N. ${ }^{\circ}$ 75, Série I. Accessed 25 October 2007 from: http://www.saudereprodutiva.dgs.pt/?cpp=1 [In Portuguese].

4. Portaria n. ${ }^{\circ}$ 741-A/2007, de 21 de Junho - Ministério da Saúde, Diário da República N. ${ }^{\circ} 118$, Série I. Accessed 25 October 2007 from: http://www.saudereprodutiva.dgs.pt/?cpp $=1$ [In Portuguese].

5. Direcção-Geral da Saúde. Circular Normativa N. ${ }^{\circ} 9 / \mathrm{SR}$ de 21 de Junho de 2007 - Interrupção Medicamentosa da Gravidez. Accessed 25 October 2007 from: http:// www.saudereprodutiva.dgs.pt/?cpp $=1$ [In Portuguese].

6. Direcção-Geral da Saúde. Circular Normativa N. ${ }^{\circ}$ 10/ SR de 21 de Junho de 2007 - Interrupção Cirúrgica da Gravidez até às 10 Semanas de Gestação. Accessed 25 October 2007 from: http://www.saudereprodutiva.dgs.pt/?cpp $=1$ [In Portuguese].

7. Direcção-Geral da Saúde. Circular Normativa No. 11/ SR de 21 de Junho de 2007 - Organização dos Serviços para Implementação da Lei 16/2007 de 17 de Abril. Accessed 25 October 2007 from: http://www.saudereprodutiva.dgs.pt/?cpp $=1$ [In Portuguese].

8. Associação para o Planeamento da Família, Consulmark. A Situação do Aborto em Portugal: Práticas, Contextos e Problemas. Sexualidade e Planeamento Familiar 2006;42/ 43:5-23. [In Portuguese].

9. Vilar D. A IVG Legal nos Hospitais Portugueses: $3^{\circ}$ Estudo - 1998/99. Sexualidade e Planeamento Familiar 1999;23/24:7-9. [In Portuguese].

10. Equipa Opções. A IVG vista pelas mulheres: Histórias de mulheres que recorrem à Linha Opções. Lisboa: Associação para o Planeamento da Família, 2009. [In Portuguese].

11. Beja V. A Interrupção Voluntária da Gravidez Legal em Portugal: Estudo Exploratório das Representações dos Técnicos de Saúde sobre os Motivos de Recurso e o Processo de Aconselhamento [MSc thesis]. Lisbon: Instituto Superior de Psicologia Aplicada 2009. [In Portuguese].

12. Baker A, Beresford T, Halvorson-Boyd G, et al. Informed consent, counseling, and patient preparation. In Paul M, Lichtenberg ES, Borgatta L, et al., eds. A clinician's guide to medical and surgical abortion. Washington, DC: National Abortion Federation 1999. Accessed 25 March 2008 from: http://www.prochoice.org/education/resources/textbook.html
13. De Bruyn M, Packer S. Adolescents, unwanted pregnancy and abortion: Policies, counseling and clinical care. Chapel Hill, NC: Ipas 2004.

14. Hyman AG, Castleman L. Woman-centered abortion care: Reference manual. Chapel Hill, NC: Ipas 2005.

15. Terki F, Malhotra U, Pawlson M. Medical and service delivery guidelines for sexual and reproductive health services, 3rd edn. London: International Planned Parenthood Federation 2004.

16. World Health Organization, Division of Reproductive Health. Post-abortion family planning: a practical guide for programme managers. Geneva: WHO 1998.

17. World Health Organization. Safe abortion: Technical and policy guidance for health systems. Geneva: WHO 2003.

18. Everett H. Aims in termination counselling. Paper presented at the Pro-Choice Forum conference Issues in pregnancy counselling: What do women need and want? 1997 May, Oxford. Accessed 15 March 2008 from: http:// www.prochoiceforum.org.uk/psy_coun4.asp

19. Murphy C. Distance or control: Abortion and counselling in Germany. Paper presented at the Pro-Choice Forum conference Issues in pregnancy counselling: What do women need and want? 1997 May, Oxford. Accessed 15 March 2008 from: http://www.prochoiceforum.org.uk/psy_coun5.asp

20. Ely GE. The abortion counseling experience: A discussion of patient narratives and recommendations for best practices. Best Pract Mental Health 2007;3:62-74.

21. Fisher B, Castle MA, Garrity JM. A cognitive approach to patient-centered abortion care. In Beckman LJ and Harvey SM, eds. The Civil War: The psychology, culture, and politics of abortion. Washington, DC: American Psychology Association 1998:301-28.

22. Holden G, Russell D, Paterson C. Abortion counselling: Issues and approaches. Paper presented at the Pro-Choice Forum conference Issues in pregnancy counselling: What do women need and want? 1997 May, Oxford. Accessed 15 March 2008 from: http://www.prochoiceforum.org.uk/psy_coun6.asp

23. Lattimer $M$. The construction of women in abortion services. Paper presented at the Pro-Choice Forum conference Issues in pregnancy counselling: What do women need and want?; 1997 May, Oxford. Accessed 15 March 2008 from: http://www.prochoiceforum.org.uk/psy_coun7.asp

24. Rasch V, Yambesi F, Massawe S. Medium and long-term adherence to postabortion contraception among women having experienced unsafe abortion in Dar es Salaam, Tanzania. BMC Pregnancy and Childbirth [serial online] 
2008;8(32). Accessed 2 August 2008 from: http:// www.biomedcentral.com/content/pdf/1471-2393-832.pdf

25. Yassin A, Cordwell D. Does dedicated pre-abortion contraception counselling help to improve post-abortion contraception uptake? J Fam Plann Reprod Health Care 2005;31:115-6.

26. Billings DL, Velásquez JF, Peréz-Cuevas R. Comparing the quality of three models of postabortion care in public hospitals in Mexico City. Int Fam Plann Perspect 2003;29:112-20.

27. Corbett MR, Turner KL. Essential elements of postabortion care: Origins, evolution and future directions. Int Fam Plann Perspect 2003;29:106-11.

28. Tabbutt-Henry J, Graff K. Client-provider communication in post-abortion care. Int Fam Plann Perspect 2003;29:126-9.

29. Carneiro Gomes Ferreira AL, Lemos A, Natal Figueiroa J, Impieri de Souza A. Effectiveness of contraceptive counselling of women following an abortion: A systematic review and meta-analysis. Eur J Contracept Reprod Health Care 2009;14:1-9.

30. Goodman S, Wolfe M, The TEACH Trainers Collaborative Working Group. Early abortion trainer's workbook, 2nd edn. San Francisco, CA: University of California San Francisco Bixby Center for Reproductive Health Research \& Policy 2007.
31. National Abortion Federation. The abortion option: A values clarification guide for health care professionals. Washington, DC: National Abortion Federation 2005.

32. Stewart FH, Darney PD. Abortion: Teaching why as well as how. Perspect Sex Reprod Health 2003;35:37-9.

33. Vala J. A análise de conteúdo. In Silva AS and Pinto JM, eds. Metodologia das ciências sociais, 10th edn. Porto: Editora Afrontamento 1999:101-28. [In Portuguese].

34. Bardin L. L'analyse de contenu. Paris: Presses Universitaires de France 1977. [In French].

35. Krippendorff K. Content analysis: An introduction to its methodology, 2nd edn. Thousand Oaks, CA: Sage Publications 2004.

36. Adler NE, David HP, Major BN, et al. Psychological factors in abortion: A review. Am Psychol 1992;47:1194-204.

37. Törnbom $M$, Ingelhammar E, Lilja $H$, et al. Decisionmaking about unwanted pregnancy. Acta Obstet Gynecol Scand 1999;78:636-41.

38. Major B, Cozzarelli C, Sciacchitano AM, et al. Perceived social support, self-efficacy, and adjustment to abortion. $J$ Pers Soc Psychol 1990;59:452-63.

39. Ringheim K. When the client is male: Client-provider interaction from a gender perspective. Int Fam Plann Perspect 2002;28:170-5.

40. Nelson ES, Coleman PK, Swager MJ. Attitudes toward the level of men's involvement in abortion decisions. $J$ Humanist Educ Dev 1997;35:217-24. 
Copyright of European Journal of Contraception \& Reproductive Health Care is the property of Taylor \& Francis Ltd and its content may not be copied or emailed to multiple sites or posted to a listserv without the copyright holder's express written permission. However, users may print, download, or email articles for individual use. 